\title{
Experiência estética no debate do filme Lakay numa universidade brasileira
}

\author{
Tarcis Prado Junior \\ Moises Cardoso' \\ Franco lacomini Júnior' \\ I - Universidade Tuiuti do Paraná (UTP) \\ Curitiba (PR), Brasil
}

Resumo: Em agosto de 2016, foi promovido um cinedebate pelo GRUDES (grupo de pesquisa em cinema e audiovisual da Universidade Tuiuti do Paraná) sobre o filme Lakay, dos cineastas Jéssica Frazão e Matheus Paladino (2016). O filme relata a vida dos imigrantes haitianos no sul do Brasil e nesse evento estavam presentes alunos de graduação da Universidade Tuiuti do Paraná. Entre esses estudantes estava um haitiano que chegara recentemente ao país. Durante o debate, ele participou ativamente contando sua história no Haiti e os motivos de sua emigração ao Brasil. Este artigo propõe uma reflexão sobre a participação desses estudantes no debate em relação à ideia de "pequenas crises" em Gumbrecht (2006). Os resultados indicam que o evento foi uma experiência estética proporcionada por meio da oscilação entre o efeito de sentido e de presença, reforçando o que defende o teórico alemão.

Palavras-chave: Lakay; Gumbrecht; imigração; haitianos.

Abstract: Aesthetic experience on the Lakay movie debate in a Brazilian university - In August 2016, a movie debate was promoted by GRUDES (a film and audiovisual research group from the Tuiuti University of Paraná) on the film Lakay, by filmmakers Jéssica Frazão and Matheus Paladino (2016). The film recounts the life of the Haitian immigrants in southern Brazil, and the event was attended by undergraduate students from the Tuiuti University of Paraná. Among them was a Haitian who had recently arrived in the country. During the debate he participated actively in telling his story in Haiti and the reasons for his emigration to Brazil. This article proposes a reflection on the participation of these students in the debate on the idea of "small crises" in Gumbrecht (2006). The results indicate that the event was an aesthetic experience provided by the oscillation between the effects of sense and presence, reinforcing the German theorist's arguments .

Keywords: Lakay; Gumbrecht; immigration; Haitians. 


\section{Introdução}

Estudos sobre imigração e deslocamentos humanos têm sido objeto de diversos trabalhos (TEIXEIRA, 2014; COGO \& SILVA, 2016, entre outros) nos últimos anos, quando a crise migratória, principalmente na Europa, adquiriu proporções alarmantes. Só em 2016, foram mais de 3 mil pessoas mortas na tentativa de chegar à Europa pelo mar Mediterrâneo' .

No Brasil, inúmeros estrangeiros chegam na tentativa de reconstruir suas vidas. Alguns vêm do Oriente Médio, outros de diferentes países sul-americanos e um grupo que tem se destacado muito no país é o dos haitianos ${ }^{2}$. O país caribenho intensificou o fluxo migratório para o Brasil a partir da guerra civil (resultado da derrubada do presidente Jean-Bertrand Aristide, em 2004³) e do terremoto que devastou a nação em $2010^{4}$, elevando o número de pessoas que chegam a diversas cidades brasileiras como São Paulo (o maior contingente de pessoas), Rio de Janeiro e algumas da região norte. No Sul, o fluxo é menor, mas uma comunidade significativa de imigrantes haitianos tem marcado presença em estados como Paraná e Santa Catarina. Este último foi cenário para o documentário "Lakay", de Jéssica Frazão e Matheus Paladino (2016), que mostra a vida de um grupo de haitianos no Vale do Itajaí. A película tem sido exibida no circuito alternativo e, principalmente, universitário (participou inclusive do VII Fórum Social Mundial das Migrações). Um dos locais de projeção foi a Universidade Tuiuti do Paraná, em Curitiba. Na ocasião, a exibição se deu no projeto CineGRUDES Debate ${ }^{5}$, evento que teve participação de um grupo de alunos do primeiro período do curso de Administração, levado pelo professor como uma das atividades daquela disciplina. Um dos alunos era um haitiano que veio recentemente ao país. Ele participou ativamente do debate, contando sua experiência como imigrante. A tela mostrou e o rapaz complementou (ora referendando, ora discordando) os depoimentos das personagens. Esse movimento criou um ambiente com as condições ideais para a tese de Gumbrecht desenvolvida em seus trabalhos de 2006 e 2010, qual seja: a experiência estética é proporcionada pela oscilação entre o efeito de sentido e o efeito de presença. Até aquele momento, conta o professor, o aluno não estava adaptado à turma. A partir do debate, ele passou a interagir com os demais colegas de curso - ou seja, o evento foi iniciador de um processo de integração do estrangeiro com aquele grupo.

1 Isso é mais do que durante todo o ano de 2015, quando 3.777 pessoas morreram durante a travessia marítima para a Europa. Disponível em: <https://br.sputniknews.com/mundo/201610286667667-crise-imigracao-2016mortes-mediterraneo/>. Acesso em: 23 jan. 2017.

2 O projeto "Estudos sobre a migração haitiana ao Brasil e diálogo bilateral" dispõe de uma pesquisa com o perfil dos haitianos no país. Disponível em: <http://www.migrante.org.br/images/arquivos/pesquisa-migrantesbrasileira-acre.pdf>. Acesso em: 23 jan. 2017.

3 Disponível em: <http://zh.clicrbs.com.br/rs/noticia/2010/01/conflitos-marcam-historia-politica-do-haiti-2776128. html>. Acesso em: 23 jan. 2017.

4 Disponível em: <http://g1.globo.com/Noticias/Mundo/0,,MUL1446514-5602,00-COBERTURA+COMPLETA+ TERREMOTO+NO+HAITI.html>. Acesso em: 23 jan. 2017.

5 O GRUDES (Grupo de pesquisa desdobramentos simbólicos do espaço urbano em narrativas audiovisuais) tem o projeto cinedebate onde são exibidos regularmente alguns filmes, especialmente com a imigração e os deslocamentos humanos na universidade, que alunos do programa de pós-graduação e de graduação da Universidade Tuiuti do Paraná. Maiores informações disponíveis em: <http://www.gpgrudes.com/>. Acesso em: 19 jan. 2017. 
O objetivo principal deste artigo é refletir sobre a participação desses estudantes no debate de Lakay em relação à ideia de "pequenas crises" em Gumbrecht (2006). O questionamento deste trabalho é pensar se o evento pode ou não ser considerado uma experiência estética. Nesse sentido, este estudo está dividido em três seções, além da introdução e considerações finais. Em "Lakay e a imigração haitiana no Vale do Itajaí (SC)", mostramos brevemente como o filme de Jéssica Frazão e Matheus Paladino (2016) relata a vida dos haitianos no sul do Brasil e como filmes como esse podem ser importantes para apresentar o cotidiano da presença estrangeira no país. Na seção "As pequenas crises em Gumbrecht", apresentamos as ideias do teórico alemão e sua tese sobre a experiência estética. Para finalizar, em "Efeito de presença e de sentido num evento universitário", discutimos a experiência estética na exibição de Lakay para uma turma de estudantes universitários, com a presença de um estudante haitiano entre eles, bem como alguns desdobramentos dessa interação.

\title{
Lakay e a imigração haitiana no Vale do Itajaí (SC)
}

Lakay (2016) é um documentário em curta-metragem que aborda a imigração haitiana ocorrida a partir de 2010 para a região do Vale do Itajaí, em Santa Catarina. Segundo seus produtores, a proposta da obra foi documentar, tendo em vista questões identitárias, a interação cotidiana desses indivíduos em um novo país, além de retratar os pontos de vista dos haitianos e daqueles que se identificam com essa comunidade acerca do processo de imigração, recepção, preconceito/xenofobia, dificuldades do idioma, adaptação e superação.

Embora não seja a proposta do estudo a análise do filme strictu sensu e tampouco a abordagem das questões de identidade imanentes, vale um comentário de Teixeira (2014), citando Yudice (2004), sobre o papel social da película:

\begin{abstract}
Os filmes mais compromissados sociologicamente, feitos com uma dinâmica da alternância entre ficção e realismo, precisam saber expor mais diacriticamente a pletóricas das identidades poliédricas, profundamente reflexivas, não tendo receio de avançar ao relato realista e profundo em suas naturezas ambivalências. Cinemas que desconstroem as hiperrepresentatividades e sensibilizam as contradições explícitas e implícitas das realidades sociais, ao mesmo tempo que melhor respeitam a gramática da cohabitação e da convivência, geralmente tensa, mas também disposta a ser provisoriamente não apenas um diagrama da esfera do cotidiano, mas um retrato verossimilhante dessas realidades, são cinemas que avançam na disposição a apontar quão inestáveis e 'incoerentes' (...) podem ser as identidades (TEIXEIRA, 2014, p. 45).
\end{abstract}

Em Lakay, algumas cenas mostram depoimentos dos haitianos e suas primeiras impressões sobre o país, como afirma um deles (figura 1) logo no início do filme: 
"Pensei que [o Brasil] era uma nação de negros. Quando cheguei a São Paulo pela primeira vez, a impressão é que era diferente. Totalmente diferente. E muito mais diferente quando cheguei a Blumenau ${ }^{\prime \prime}$ (LAKAY, 2016). Alguns estão contentes com seu trabalho, outros decepcionados com o que encontraram no país em relação à expectativa de ganhar dinheiro. Outros, ainda, abordam o preconceito sofrido no Sul do país (figura 2), ora acreditando que ele não existia: "Todo mundo não gosta de preto, né? Mas de verdade, não é verdade. Nunca uma pessoa fala mal de mim (...). Pra mim, Blumenau é uma cidade bem tranquila" (LAKAY, 2016). E ora afirmado que ele está presente, sim, em seu dia a dia: "Quando você vai caminhando ao lado de uma pessoa branca, começa a afastar um pouco, pensando que você é um ladrão" (LAKAY, 2016).

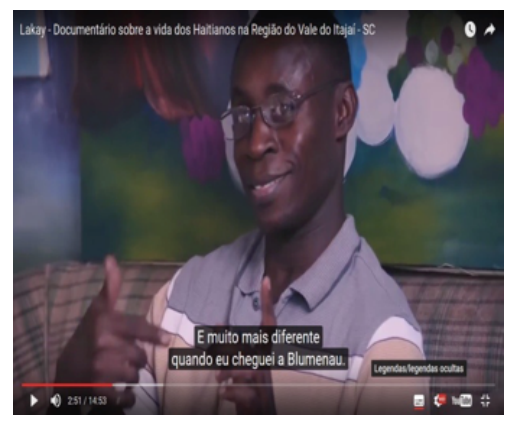

Fig.1. Primeiras impressões. Fonte: Lakay, 2016.

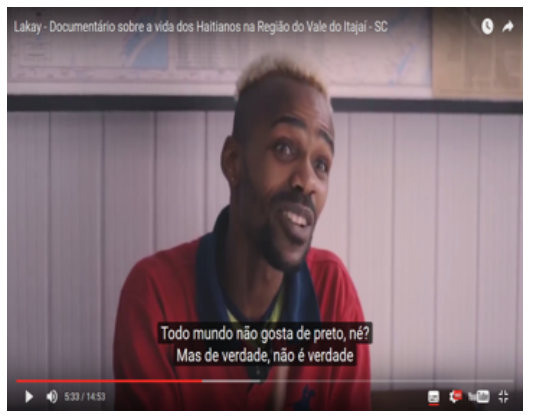

Fig.2. Preconceito racial na cidade. Fonte: Lakay, 2016.

Especificamente sobre as questões racial e xenofóbica, Jéssica Frazão, uma das cineastas do filme afirma que "o Brasil é um país de imigrantes, e os estados do RS e SC são exemplos fortes disso. A barreira do preconceito precisa ser vencida diariamente, nas particularidades, nas generalizações, no cotidiano" (EU SEM FRONTEIRAS, 2016). Seu filme vai nesse sentido, jogando luz sobre uma temática que tem se tornado cada vez mais discutida em território nacional, frente às crises migratórias.

Os haitianos no país enfrentam também as consequências da imagem que deles é feita pela mídia na sua nova terra, e que vai formar o imaginário do imigrante haitiano entre o povo brasileiro.

Assim, a visibilidade pública dessa imigração produzida pela mídia brasileira pode ser pensada como resultado e ao mesmo tempo instância que vai evidenciar e (re) atualizar esses enlaces geopolíticos e imaginários simbólicos entre Brasil

6 Em setembro de 2017 a cidade de Blumenau (SC) foi notícia no país por conta de manifestações nazistas e racistas naquela cidade. Um cartaz foi colado em diversos lugares da cidade fazendo apologia ao preconceito contra negros: "Negro, macumbeiro, antifa, estamos de olho em você" (Disponível em: <http://www. diariodocentrodomundo.com.br/blumenau-os-cartazes-contra-negros-e-macumbeiros-e-gestapo-brasileirapor-mauro-donato/>. Acesso em: 30 set. 2017). Isso denota a dimensão do choque que deve ter sido para o haitiano encontrar um país onde (supostamente) negros não seriam bem-vindos. 
e Haiti, que operam como antecedentes e também impulsionadores dos fluxos migratórios de haitianos para o país (COGO; SILVA, 2016, p. 6).

Sendo assim, a inserção dos novos "visitantes" da sociedade brasileira vai acontecer também a partir das narrativas midiáticas sobre essa chegada. Nos seus estudos sobre como a mídia apresenta esse fluxo migratório, Cogo e Silva (2016) apontam que as narrativas possuem um tom discriminatório e pejorativo:

Na dimensão da alteridade de um Outro (Haiti) frente a um Nós (Brasil), as narrativas vitimam os haitianos como indivíduos e povo, associando-os a uma realidade de pobreza e catástrofe. Ao chegar ao Brasil, eles enfrentam dificuldades, mas encontram uma situação "melhor do que no Haiti" (COGO; SILVA, 2016, p. 9).

É envolto a essa atmosfera que o filme Lakay se desenvolve e é esse também o contexto que vai sedimentar o terreno para a experiência estética na ideia das pequenas crises em Gumbrecht (2006) e a presença do haitiano no debate sobre a obra de Jéssica Frazão e Matheus Paladino.

\section{As pequenas crises em Gumbrecht}

Gumbrecht (2006) chama de pequenas crises os momentos em que o fluxo do cotidiano é interrompido por acontecimentos envolvendo objetos que durante muito tempo nos foram familiares e, de repente e sem qualquer motivo visível, ganham uma aparência estranha ou causam um sentimento de estranheza. $\mathrm{O}$ autor ilustra esse conceito a partir da sua experiência ao fazer a barba.

Acontece comigo, mais ou menos uma vez por semana, que, ao fazer a barba de manhã, as minhas orelhas aparecem como um acréscimo alheio ao meu rosto, na maneira com que aparecem no espelho. Sua forma se torna estranha, quase grotesca; elas parecem supérfluas e desnecessárias em relação à sua função. Às vezes sinto um embaraço por sua causa, mesmo não havendo ninguém olhando para mim (GUMBRECHT, 2006, p. 55).

A experiência estética nos mundos cotidianos, apesar de apontar para um novo estado universal do mundo, sempre será uma exceção que, de maneira totalmente natural e de acordo com cada situação individual, desperta em nós o desejo de detectar as condições (excepcionais) que a tornaram possível (GUMBRECHT, 2006). O autor então propõe algumas situações em que essas crises no cotidiano podem acontecer.

A primeira delas é o exemplo do papel higiênico nos hotéis mundo afora. Em muitos desses estabelecimentos, o pessoal da limpeza deixa o papel dobrado, bem ao estilo origami, para que o hóspede talvez sinta que aquele local é diferente da sua casa, como 
se representasse uma quebra na sua rotina numa versão bastante prosaica. Gumbrecht tem uma pista mais pragmática sobre esses ornamentos: seria uma forma de os funcionários preverem quando fosse preciso uma nova troca de rolos. No entanto (GUMBRECHT, 2006 p. 51), os ornamentos podem desencadear um tipo de experiência estética que se impõe como uma interrupção dentro do fluxo da nossa vida cotidiana. Quer dizer: a vida comum, nas mais simples situações, pode suscitar momentos em que a rotina é quebrada por objetos, cores, formas, barulhos, sensações - enfim, movimentos sinestésicos que podem proporcionar experiências estéticas das quais as pessoas sempre se recordarão.

A segunda situação que o autor aborda em seu texto é o exemplo do movimento "Nova Objetividade", muito discutida entre os protagonistas do Bauhaus, onde o valor estético de um objeto estaria na sua forma voltada à sua funcionalidade.

Trata-se da convicção de que um máximo de adaptação da forma de um objeto à sua função produziria necessariamente o mais alto valor estético. "Quanto mais funcional, mais bonito", teria sido o lema apropriado (GUMBRECHT, 2006, p. 51).

A terceira situação que Gumbrecht aborda no texto é o cenário (o "frame") em que algo se desenvolve e que tem o poder de transformar o valor das coisas banais em estéticas, por exemplo, o que chamamos de "comida chique", "roupa da moda" e elegância na solução de problemas matemáticos complexos. Para ele (GUMBRECHT, 2006, p. 52), o que esses tipos de "experiência estética na vida cotidiana" compartilham é sua condição de "excepcionais" dentro de um contexto maior. Mas elas são diferentes entre si na medida em que cada uma depende de uma constelação diferente de circunstâncias (poderíamos dizer também: na medida em que cada uma pertence a uma outra modalidade de crise).

Gumbrecht ainda cita Kant, fazendo alusão aos "prazeres desinteressados", prazer que independe dos propósitos e das funções que perseguimos nos nossos mundos cotidianos (2016, p. 53). Para o filósofo alemão (de acordo com Gumbrecht), a experiência estética produz sentimentos íntimos, uma "finalidade sem fim".

Para Gumbrecht (2006, p. 54), o conteúdo da experiência estética seria definido pelos sentimentos íntimos, as impressões e as imagens produzidos pela nossa consciência enquanto inacessíveis aos nossos mundos historicamente específicos. A impressão de uma "finalidade sem fim", por exemplo, de um "Ser desvelado" ou de um objeto e seu conceito e sua "aparência", uma vez que são desvinculados do seu contexto. Diferentemente desse conteúdo, os objetos da experiência estética seriam as coisas suscetíveis de desencadear tais sentimentos, impressões e imagens: o templo grego, no ensaio de Heidegger, por exemplo; ornamentos de papel de parede e o mar para Kant; e, de acordo com Seel, qualquer objeto. As condições da experiência estética são circunstâncias situacionais historicamente específicas nas quais a experiência estética estaria baseada. "Desinteresse", por exemplo, isto é, a distância diante de todos os propósitos práticos, que vem sendo 
adotado como uma condição universal da experiência estética (mesmo que, ao que tudo indica, tenha se tornado pressuposição na cultura ocidental somente desde o século XVIII).

Os conteúdos da experiência estética nos apresentam como epifânicos, isto é, eles aparecem repentinamente ("como um relâmpago") e desaparecem de repente e irreversivelmente, sem permitir-nos permanecer com eles ou estender sua duração (GUMBRECHT, 2006, p. 55). Ou seja, como o próprio autor estabelece na sua ideia de produção de sentido, a epifania é tripartite, envolvendo a emersão, espacialidade e ocorrência, pois no momento em que o objeto da experiência estética surge e provoca a sensação (intensidade), esta parece vir do nada. Desse modo, este aparecimento é materializado, o que exige uma dimensão (ou perspectiva) espacial e então, finalmente, o caráter de evento da epifania também segue uma certa lógica trinária: se ocorrer, não se sabe quando e qual intensidade terá, mas se surgir, sempre desaparecerá. "[...] a temporalidade em que sentimos [...] será sempre a temporalidade de um momento" (GUMBRECHT, 2010, p. 143).

Por fim, o autor conclui seu texto sobre as pequenas crises mostrando que a experiência estética de fruir uma música erudita moderna, ou - no exemplo que ele mesmo nos fornece (p. 63) - certas formas de jazz altamente sofisticadas podem exigir um grau tão grande de conhecimento sobre a música que essa experiência estética poderia até provocar a exclusão social.

O efeito de presença, de proximidade, que certos objetos, situações ou pessoas, poderiam proporcionar, em condições de excepcionalidade (no caso deste artigo, a condição ordinária de estar numa sala de aula convencional de uma universidade, com carteiras, quadro negro e outros objetos próprios daquele ambiente, porém para assistir a um filme - e, nesse caso então, como se fosse uma sala de cinema - com a presença de alguém que parece ter "saído da tela", ali com todos os alunos ou "espectadores") do automatismo da vida cotidiana configura o valor estético a essa interação. E é isso que vamos desenvolver um pouco mais na seção seguinte, fazendo uma aproximação com a ideia de imaginário em Maffesoli e Silva.

\section{Efeito de presença e de sentido num evento universitário}

Segundo Gumbrecht, "uma 'presença' é algo tangível, com o qual se mantém uma relação no espaço e que tem algum tipo de impacto sobre corpo e sentidos" (GUMBRECHT, 2010).

para ser percebida, uma substância tem de ter forma; e se, finalmente aceitarmos [...] que o componente de presença na tensão ou oscilação que constitui a experiência estética nunca pode ser estabilizado, segue-se que sempre que um objeto da experiência estética surge e por momentos produz em nós essa sensação de intensidade, ela parece vir do nada (GUMBRECHT, 2010, p. 141). 
A interação entre o filme, o haitiano e a turma presente no evento pôde propiciar o surgimento de experiências sensíveis ${ }^{7}$ como assinala Sodré (2006). Nesse sentido, por que não pensar, inclusive (ou principalmente), nas experiências ligadas ao afeto? Primeiramente, o que se viu ali, na verdade, foram momentos felizes (GUMBRECHT, 2006), que, numa analogia a Deleuze e Guattari, são os "que se conectam à fugacidade da obra do pintor e dos segundos de contemplação que poderiam durar uma eternidade" (DELEUZE; GUATTARI, 2009, p. 167-168).

A conexão entre o filme, a turma e o haitiano encontra aderência inclusive no imaginário, que, para Maffesoli (2001), funciona como interação - e sobre isso, inclusive, o sociólogo francês nos fornece um exemplo bastante particular:

Quando faço uma palestra me acontece, às vezes, de perceber algo que ultrapassa o que estou dizendo. Numa conferência, há sempre uma construção, algo que é argumentado. Mas, muitas vezes, na relação com o público, surge uma forma de intensidade, de partilha, de sintonia, de vibração. Há, nisso, alguma coisa que encontra eco não somente na razão, mas também nos sentimentos dos ouvintes (MAFFESOLI, 2001, p. 77).

Silva (2017, p. 145), burilando uma relação entre imaginário, diferença e fantasia ${ }^{8}$, assinala que "o imaginário não é um quadro de Vermeer, mas o que esse quadro pode gerar como fantasia na percepção do observador". Nesse sentido, poderíamos pensar: quais fantasias então teriam sido geradas na mente de cada estudante ali naquela sala de aula ao observar a materialização do personagem do filme ali entre eles? Qual o imaginário daquela turma agindo como motor ${ }^{9}$ (SILVA, 2012), naquela noite? Em que atmosfera de partilha (MAFFESOLI, 2001) pode ter se configurado aquela experiência? Sem dúvida, aquele momento foi uma ruptura na ordinaridade da vida acadêmica daqueles jovens, provocando alguns instantes de felicidade, nos termos do autor alemão.

Os momentos felizes a que se referem Gumbrecht (2006) podem também ser os equivalentes às fraturas em Greimas ${ }^{10}$. Dessa forma, no evento, esse momento (fratura) acontece especialmente quando, no espaço para comentários da turma (após o filme), o colega haitiano relata suas experiências de vida, em seu país de origem, promovendo uma conexão ficção-realidade entre os participantes, incluindo também a presença física da cineasta Jéssica Frazão contando sobre o processo de produção do filme (figuras 3 e 4). Ou seja, as condições materiais que possibilitam a emergência do sentido (SILVEIRA, 2010)

7 As experiências sensíveis podem orientar-se por estratégias espontâneas de ajustamento e contato nas situações interativas, mas salvaguardando sempre para o indivíduo um lugar exterior aos atos puramente linguísticos, o lugar singularíssimo do afeto (SODRÉ, 2006, p. 11).

8 Em "Diferença e Descobrimento: o que é o imaginário? A hipótese do excedente de significação" (Sulina, 2017), Juremir Machado da Silva afirma que "o que justifica o sucesso de uma obra é a diferença produzida" (p. 144).

9 Para Silva (2012, p. 11-12), o imaginário pode ser duas coisas: reservatório (imagens, sentimentos, lembranças e experiências) e motor (acelerador que imprime velocidade à possibilidade de ação).

10 Greimas chama de "fraturas" as situações do cotidiano que quebram a rotina, provocando uma experiência estética. 
estão estabelecidas e a produção de presença se evidencia pela apreensão de "todos os tipos de eventos e processos nos quais se inicia ou se intensifica o impacto dos objetos 'presentes' sobre corpos humanos" (GUMBRECHT, 2010, p. 13). Temos aqui então a materialidade do nosso objeto de estudo para a experiência estética em Lakay, posto que todos os atores (estudantes, cineasta, colega haitiano) estão inseridos fisicamente num mesmo cenário, a sala de aula onde foi exibido o filme, e a experiência estética se desenvolve não posteriormente ou num devir, mas no momento em que todos ali estão. Lembrando que Gumbrecht defende um tipo de aderência às "coisas do mundo", à presença no instante e à "intensidade do momento" (SILVEIRA, 2010, p. 2), além de evidenciar que "[...] a tensão / oscilação entre efeitos de presença e efeitos de sentido dota o objeto de experiência estética de um componente provocador de instabilidade e desassossego" (GUMBRECHT, 2010, p. 137).

Podemos pensar ainda no imaginário (por meio das notícias sobre o Haiti veiculadas pela mídia brasileira e internacional - e também sobre filmes como o próprio Lakay) de todos $^{11}$ em relação ao colega haitiano, que poderia ser visto (imaginado) como, entre outras imagens: a de um sofredor no país estranho, de um sobrevivente da catástrofe no seu local de origem, ou de alguém que precisaria estudar muito para se recolocar no mercado. Mas como ensina Maffesoli sobre a ideia de imaginário:

\begin{abstract}
Não é a imagem que produz o imaginário, mas o contrário. A existência de um imaginário determina a existência de conjuntos de imagens. A imagem não é o suporte, mas o resultado. Refiro-me a todo tipo de imagens: cinematográficas, pictóricas, esculturais, tecnológicas e por aí afora. Há um imaginário parisiense que gera uma forma particular de pensar a arquitetura, os jardins públicos, a decoração das casas, a arrumação dos restaurantes, etc. O imaginário de Paris faz Paris ser o que é. Isso é uma construção histórica, mas também o resultado de uma atmosfera e, por isso mesmo, uma aura que continua a produzir novas imagens (MAFFESOLI, 2001, p. 76-77).
\end{abstract}

No entanto, num contraste ao imaginário da turma (e possivelmente de outros presentes no evento) o colega haitiano mostrou que tinha uma experiência como empresário, falava quatro idiomas e tinha uma vida relativamente confortável no Brasil. Contou que um irmão era médico e morava no estado do Mato Grosso, que já atuara como empresário e também em organizações humanitárias em seu país de origem.

O relato do estudante haitiano foi assistido com bastante atenção pelos presentes - nem o hábito de consultar o celular a todo o momento tomou forma naquela ocasião. Todos quietos, escutavam atentos o depoimento do colega. Ao final ele foi aplaudido

11 É preciso compreender que não existe um imaginário, existem imaginários, que são mutantes (MAFFESOLI, 2017). Ou seja, as mutações no imaginário da turma podem ter ocorrido naquele momento do depoimento do colega haitiano, contribuindo para a formação, por exemplo, de uma nova ideia de Haiti, que não a que os veículos de comunicação têm mostrado no Brasil, a saber: a de um país pobre, em guerra permanente e com pessoas sem perspectiva alguma. 
efusivamente, não apenas pelo conteúdo, tampouco pela forma de seu discurso, mas principalmente pela interação ali proporcionada, talvez embrionária de um vínculo afetivo que surgiria entre ambos (colega e turma), que destacaremos posteriormente.

Esse vínculo encontra eco em Caetano (2011), que, ao abordar os estudos de Gumbrecht sobre o estético no cotidiano, assinala:

O tratar dos efeitos de presença nas interações humanas, entre os quais reconhece tanto valores eufóricos quanto disfóricos (...) não descarta os vieses sensorial, afetivo e vinculante das interações humanas; ao contrário, toma-os como sustentáculos dos efeitos de presença (CAETANO, 2011, p. 15).

O ato de assistir às cenas do filme tendo ali junto o colega haitiano e, especialmente, sua posterior performance no debate sobre o filme, podem ter propiciado uma experiência estética por meio da oscilação do efeito de sentido - ao ver as personagens da película (ainda mais cientes de que eram reais, pois tratava-se de um documentário). A experiência é intensificada, ao mesmo tempo, por estar ao lado de alguém que bem poderia ter saído diretamente daquela obra (efeito de presença). Como destaca Gumbrecht (2010):

[...] a dimensão de presença predominará sempre que ouvimos música - e, ao mesmo tempo, é verdade que algumas estruturas musicais são capazes de evocar certas conotações semânticas. Mas, por menor que em determinadas circunstâncias mediáticas se possa tornar a participação de uma ou da outra dimensão, penso que a experiência estética - pelo menos em nossa cultura sempre nos confrontará com a tensão, ou a oscilação, entre presença e sentido (GUMBRECHT, 2010, p. 139).

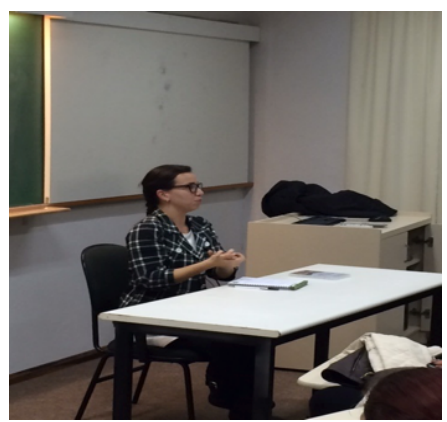

Fig.3. Jéssica Frazão participa do debate. Fonte: Autor, 2016.

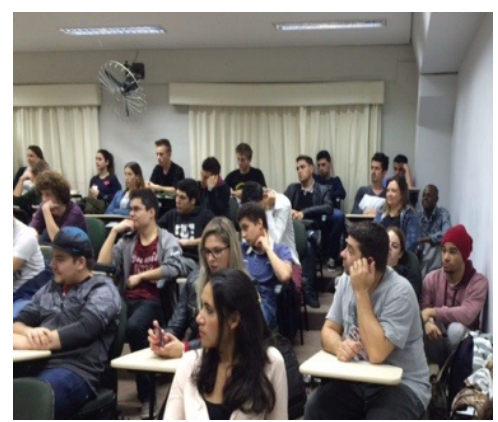

Fig.4. Alunos assistem ao debate. Fonte: Autor, 2016.

Algumas reflexões podem ser feitas a partir do evento na universidade sobre a oscilação entre o efeito de sentido e de presença. Segundo Gumbrecht (2006), a experiência estética dependeria do efeito de presença, obteria dela as condições propícias à sua ocorrência. Nesse sentido, podemos pensar na possibilidade da ocorrência 
dessa experiência estética por ação de uma espécie de bloco de sentimentos (DELEUZE; GUATTARI, 2009), personificado na figura do estudante haitiano. Será que a presença dessa pseudo personagem não ensejaria uma espécie de obra de arte como (ainda nas palavras dos autores franceses) algo que provocasse (afectos) seus colegas e demais presentes e também este fosse afetado por eles? Lembrando que mesmo os blocos de sensações, mesmo as obras de arte, têm suas fissuras (DELEUZE; GUATTARI, 2009), que nelas se pode fazer algo - e nisso podemos também pensar numa relação com os vazios em HAN (2014), que avalia a sociedade da transparência (no caso, a nossa) como vazia de sentido (pois este só pode acontecer numa sociedade lenta). Naquele evento, então, o ato de assistir a um filme, comentá-lo, apreciá-lo só foi possível por meio da relativa lentidão ${ }^{12}$ (desaceleração) do processo, numa ruptura daquela cotidianidade (GUMBRECHT).

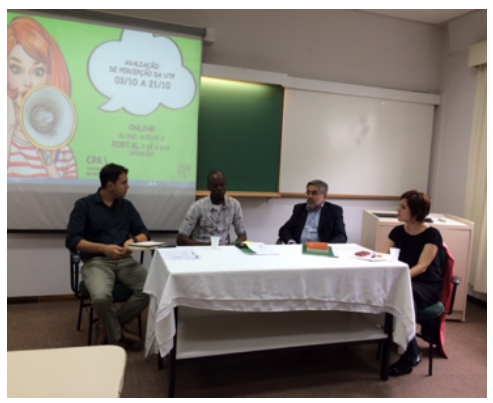

Fig.5. Aluno participa de fórum de migração. Fonte: Autor, 2016.

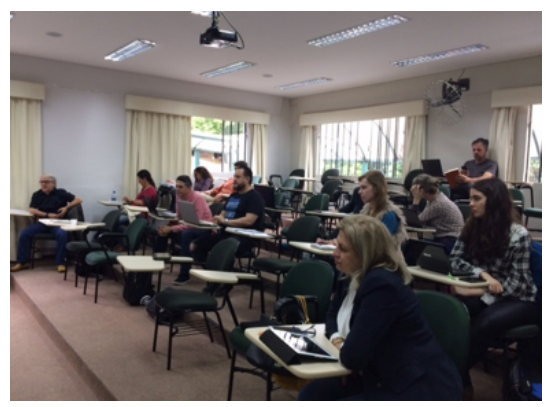

Fig.6. Participantes do fórum de migração. Fonte: Autor, 2016.

A experiência estética é também aquela que pode acontecer nas pequenas crises do cotidiano, fora do domínio do artístico. As condições favoreceram tal experiência por conta do inesperado das cenas do filme (os estudantes não sabiam que se trataria de um filme sobre imigração haitiana), que possivelmente tenha causado um efeito de sentido, já que o que estava na tela, por mais distante que estivesse do dia a dia daqueles alunos, começaria a ter relevância pela presença do aluno estrangeiro entre eles.

Ao final do filme, quando a mediadora disponibiliza a palavra para comentários da plateia, o aluno estrangeiro se levanta e diz: "Bom, não tenho como não comentar um filme que é sobre a minha história, então vamos lá". E aí começa a corroborar alguns depoimentos das personagens, "corrigir" o de alguns e incluir informações novas, principalmente as relativas a sua adaptação à cidade. Um trecho de seu depoimento que impressionou bastante os estudantes ${ }^{13}$ foi quando seu colega estrangeiro contou sobre sua trajetória acadêmico-cultural e também a disposição para aceitar um trabalho no país que não era o que desejava, mas que, no momento, seria o necessário para sua subsistência.

12 Entendemos como relativa lentidão o fato de hoje em dia as pessoas assistirem a um filme ou série ou algo do tipo sempre com alguma pressa, e nesse evento o filme foi "degustado" por todos ali.

13 Alguns alunos comentaram com o professor que ficaram surpresos com as informações que seu colega estrangeiro forneceu. Disseram também jamais ter imaginado que a imigração haitiana era "aquilo tudo". 
Esse depoimento e a interação com a tela levou o grupo ali reunido a uma experiência estética, pois no tensionamento, na oscilação entre a tela e o testemunhal do haitiano, é que se criaram as condições ideais para o preenchimento dos espaços vazios (em Deleuze e Guattari) em que a experiência estética pode efetivamente acontecer.

\section{Considerações finais}

Os desdobramentos da participação dos alunos da universidade no evento Cinedebate do GRUDES revelaram uma aproximação maior da turma em relação ao colega haitiano e deste com ela. Até aquele momento (segundo conta o professor da disciplina), o estrangeiro não tinha participação efetiva em sala de aula e não era visto interagindo com os colegas. A partir de então, houve um movimento de interação, com abertura de cada um dos lados. Não há elementos mais sólidos (e comprobatórios) para afirmar que a participação no debate foi o que propiciou essa mudança na relação entre eles, porém indicam que foi isso o que aconteceu a partir daquela atividade. O imigrante, outrora tímido e cabisbaixo, após o evento começou a emitir opiniões em sala, a rir junto com os colegas. A turma que, antes, era indiferente (quiçá resistente àquele estudante), agora o provocava em brincadeiras e também o consultava sobre determinados assuntos, especialmente em relação ao empreendedorismo, já que todos então souberam da sua história como empresário no Haiti, além de sua rica bagagem cultural.

Outro efeito da participação do aluno no Cinedebate foi o convite feito pelo coordenador do programa de pós-graduação da universidade para atuar como um dos participantes da mesa de um evento sobre migrações na universidade (figuras 5 e 6), ao lado de pesquisadores renomados no assunto.

O que houve então naquela noite de agosto de 2016 foi uma experiência estética possibilitada por meio da oscilação entre o efeito de sentido e o de presença, conforme Gumbrecht (2006), e que alterou o curso da relação entre o estrangeiro e seus colegas, impulsionados por aquele evento. Em outras palavras: a presença do estudante haitiano começou a fazer sentido (para a sala e para ele) daquele momento em diante.

Tarcis Prado Junior é professor dos cursos de Comunicação Social da Universidade Tuiuti do Paraná (UTP), doutorando do PPGCOM em Comunicação e Linguagens da Universidade Tuiuti do Paraná (UTP).

tarcisjr@yahoo.com.br

Moises Cardoso é publicitário, jornalista e professor no curso de Publicidade e Propaganda (FURB e FAMEG), doutorando 
no Programa de Pós-Graduação em Comunicação e Linguagens (UTP). É membro do grupo de estudos JORXXI (PPGCom/UTP).

beiocardoso@gmail.com

Franco lacomini Júnior é jornalista e professor na Faculdade Fidelis, doutorando no Programa de Pós-Graduação em Comunicação e Linguagens (UTP). É membro do grupo de estudos JORXXI do PPGCom UTP.

fiacomini@gmail.com

\section{Referências}

BLUMENAU, os cartazes contra "negros e macumbeiros" e a Gestapo brasileira. DIARIO DO CENTRO DO MUNDO. Disponível em: <http://www.diariodocentrodomundo.com.br/blumenau-os-cartazescontra-negros-e-macumbeiros-e-gestapo-brasileira-por-mauro-donato/>. Acesso em: 30 set. 2017.

CAETANO, K. Presenças do sensível nos processos interacionais. Revista Galáxia (versão online). São Paulo: PUCSP, n. 22, p. 12-24, dez. 2011.

COBERTURA completa: terremoto no Haiti. G1. Disponível em: <http://g1.globo.com/Noticias/ Mundo/0,,MUL1446514-5602,00-COBERTURA+COMPLETA+TERREMOTO+NO+HAITI.html>. Acesso em: 23 jan. 2017.

COGO, D; SILVA, T. Entre a 'fuga' e a 'invasão': alteridade e cidadania da imigração haitiana na mídia brasileira. Revista FAMECOS (Online), v. 23, p. 1-18, 2016. Disponível em: <file://C:/Users/ tarcis/AppData/Local/Temp/21885-90516-3-PB.pdf>. Acesso em: 30 set. 2017.

CONFLITOS marcam história política do Haiti. CLICRBS. Disponível em: <http://zh.clicrbs.com.br/rs/ noticia/2010/01/conflitos-marcam-historia-politica-do-haiti-2776128.html>. Acesso em: 23 jan. 2017.

CRISE MIGRATÓRIA: 2016 registra maior número de mortes na história do mediterrâneo. Sputnik News Brasil. Disponível em: <https://br.sputniknews.com/mundo/201610286667667-crise-imigracao2016-mortes-mediterraneo/>. Acesso em: 23 jan. 2017.

DELEUZE, G.; GUATTARI, F. ?Qué es la filosofía? Barcelona: Editorial Anagrama, 2009.

EU SEM FRONTEIRAS. Lakay: um documentário sobre a imigração e adaptação dos haitianos em Santa Catarina. Eu sem Fronteiras, 2016. Disponível em: <https://www.eusemfronteiras.com.br/ lakay-um-documentario-sobre-imigracao-e-adaptacao-dos-haitianos-em-santa-catarina/>. Acesso em: 25 jan. 2017.

GREIMAS, A. J. Da Imperfeição. São Paulo: Hacker Editores, 2002.

GRUDES. Grupo de Pesquisa Desdobramentos Simbólicos do Espaço Urbano em Narrativas Audiovisuais, 2016. Disponível em: <http://www.gpgrudes.com/>. Acesso em: 19 jan. 2017.

GUMBRECHT, H. U. Pequenas crises. Experiência estética nos mundos cotidianos. In: GUIMARÃES, C. et al (Orgs.). Comunicacão e experiência estética. Belo Horizonte: Ed. UFMG, 2006.

Produção de presença: o que o sentido não consegue transmitir. Rio de Janeiro: Contraponto, Ed. PUC-Rio, 2010. 
HAN, B. C. A sociedade da transparência. Lisboa: Relógio d’Água, 2014.

LAKAY. Direção de: Jéssica Frazão e Matheus Paladino, 2016. Disponível em: <https://www.youtube. com/watch?v=BUGhDx7JDPY>. Acesso em: 18 jan. 2017.

MAFFESOLI, M. "O imaginário é uma realidade" (entrevista a Juremir Machado da Silva), In: Revista Famecos, mídia cultura e tecnologia, n. 15, v. 8. Porto Alegre: Edipucrs, 2001. Disponível em: <http:// revistaseletronicas.pucrs.br/ojs/index.php/revistafamecos/article/view/3123 >. Acesso em: 24 jan. 2017.

Entrevista concedida a Tarcis Prado Júnior. Curitiba, 25 Mai. 2017.

PROJETO estudos sobre a migração haitiana ao Brasil e diálogo bilateral. Instituto Migrações e Direitos humanos. Disponível em: $<$ http://www.migrante.org.br/migrante/index.php?option=com_co ntent\&view=article\&id=252: projeto-estudos-sobre-a-migracao-haitiana-ao-brasil-e-dialogo-bilateral \&catid=89\&ltemid=1210>. Acesso em: 23 jan. 2017.

SILVA, J. M. As tecnologias do imaginário. 3. ed. Porto Alegre: Sulina, 2012.

. Diferença e descobrimento. O que é o imaginário? A hipótese do excedente de significação. Porto Alegre: Sulina, 2017.

SILVEIRA, F. Além da atribuição de sentido. In: Verso e Reverso n. 57, vol. 24, p. 183-186, 2010. Disponível em: < http://revistas.unisinos.br/index.php/versoereverso/article/viewFile/683/103>. Acesso em: 12 set. 2017.

SODRÉ, M. As estratégias sensíveis: afeto, mídia e política. Petrópolis/RJ: Ed. Vozes, 2006.

TEIXEIRA, R. T. Cinema, identidade e memória: a produção da alteridade migratória na cinematografia espanhola desde La Aldea Maldita a Princesas. Revista Latinoamericana Comunicación Chasqui, v. 125, p. 40-49, 2014. 